with protocols is problematic. A similar problem has been described in a study from Belgium, where 234 different regimens were used in the antimicrobial prophylaxis of 19,746 surgical patients. ${ }^{22}$ Duration of prophylaxis in our study was $\leqslant 24$ hours in $91 \%$ of patients. Following inappropriate omission, the most commonly detected error was too long postoperative administration of antimicrobials. There is a major misconception among many surgeons about the need for prolonged postoperative use of antimicrobial prophylaxis in preventing operative-site infections. ${ }^{23}$ There are abundant data to show that prolonged postoperative dosing of antimicrobials does not provide additional benefit. ${ }^{8}$ The results of the study were discussed with the surgical teams, accentuating department-specific errors. A follow-up audit is currently being planned.

In summary, this prospective audit of 1,631 surgical procedures revealed that $85 \%$ of patients received appropriate surgical prophylaxis. However, $31 \%$ of those who did not receive prophylaxis should have received it. In patients receiving antimicrobials, the most common mistake was prolonged prophylaxis ( $>24$ hours). Predictors of procedures for which prophylaxis was inadvertently omitted were identified; performance varied widely among departments. Feeding this information back to surgeons could improve adherence to recommended guidelines and may contribute to reduced wound infection rates. The repetitive conduct of audits of surgical prophylaxis probably should be part of the routine activity of infection control teams.

\section{REFERENCES}

1. Haley RW, Culver DH, White JW, Emori TG. The national nosocomial infection rate. A new need for vital statistics. Am J Epidemiol 1985;121:159-167.

2. Pittet D, Ducel G. Infectious risk factors related to operating rooms. Infect Control Hosp Epidemiol 1994;15:456-462.

3. Green MS, Rubinstein E, Amit P. Estimating the effects of nosocomial infections on the length of hospitalization. J Infect Dis 1982;145:667-672.
4. Haley RW, Schaberg DR, Von Allmen SD, McGowan JE. Estimating the extra charges and prolongation of hospitalization due to nosocomial infections: a comparison of methods. J Infect Dis 1980;141:248-257.

5. McGowan JE Jr. Cost and benefit of perioperative antimicrobial prophylaxis: methods for economic analysis. Rev Infect Dis 1991; 13(suppl 10):S879-S889.

6. Kernodle DS, Kaiser AB. Postoperative infections and antimicrobial prophylaxis. In: Mandell GL, Bennett JE, Dolin R, eds. Princibles and Practice of Infectious Diseases. 4th ed. New York, NY: Churchill Livingstone; 1995:2742-2756.

7. Polk HC Jr, Wilson MA. Systemic antimicrobial prophylaxis in surgery. In: Fry DE, ed. Surgical Infections. Boston, MA: Little, Brown \& Co; 1995:127-133.

8. Dellinger EP, Gross PA, Barrett TL, Krause PJ, Martone WJ, McGowan $\mathrm{JE} \mathrm{Jr}$, et al. Quality standard for antimicrobial prophylaxis in surgical procedures. Clin Infect Dis 1994;18:422-427.

9. Antimicrobial prophylaxis in surgery. Med Lett Drugs Ther 1992;34:5-8.

10. Paluzzi RG. Antimicrobial prophylaxis for surgery. Med Clin North Am 1993;77:427-441.

11. Yinnon AM, Schlesinger Y. Recommendations for Usage of Antimicrobial in Common Clinical Conditions. Pocket Book (in Hebrew), 2nd ed. Jerusalem, Israel: GlaxoWellcome; 1996.

12. Abramov D, Jeroukhimov I, Yinnon AM, Abramov Y, Avissar E, Jerassy $Z$, et al. Antibiotic prophylaxis in umbilical and incisional hernioplasties: a randomized prospective trial. EurJ Surg 1996;162:945-948.

13. Glantz SA. Primer of Biostatistics. 3rd ed. New York, NY: McGraw-Hill, Inc; 1992:67-144.

14. Wenzel RP. Preoperative antibiotic prophylaxis. $N$ Engl J Med 1992;326:337-339.

15. Shapiro M. Perioperative prophylactic use of antibiotics in surgery: principles and practice. Infect Control 1982;3:38-40.

16. Widdison AL, Pope NR, Brown EM. Survey of guidelines for antimicrobial prophylaxis in surgery. $J$ Hosp Infect 1993;25:199-205.

17. Davey PG, Parker SE, Malek MM. Pharmacoeconomics of antimicrobial prophylaxis. J Antimicrob Chemother 1993;31(suppl B):107-118.

18. Schlesinger $Y$, Paltiel $O$, Yinnon AM. Analysis and impact of infectious diseases consultation. $J$ Hosp Infect 1998;40:39-46.

19. Finkelstein R, Reinhertz G, Embom A. Surveillance of the use of antibiotic prophylaxis in surgery. Isr J Med Sci 1996;32:1093-1097.

20. Lizan-Garcia M, Garcia-Caballero J, Asensio-Vegas A. Risk factors for surgical-wound infection in general surgery: a prospective study. Infect Control Hosp Epidemiol 1997;18:310-315.

21. Classen DC, Evans RS, Pestotnik SL, Horn SD, Menlove RL, Burke JP The timing of prophylactic administration of antibiotics and the risk of surgical-wound infection. N Engl J Med 1992; 326: 281-286.

22. Kurz X, Mertens R, Ronveaux O. Antimicrobial prophylaxis in surgery in Belgian hospitals: room for improvement. Eur J Surg 1996;162:15-21.

23. Ehrenkranz NJ. Antimicrobial prophylaxis in surgery: mechanisms, misconceptions, and mischief. Infect Control Hosp Epidemiol 1993;14:99-106.

\title{
Epidemiology of Catheter-Associated Bloodstream Infections
}

\section{Gina Pugliese, RN, MS Martin S. Favero, PhD}

Gastmeier and coinvestigators from the Institut fur Hygiene, Freie Universitat Berlin, Germany, report that the incidence of catheter-associated primary bloodstream infections (BSIs) in Germany, as defined by the $\mathrm{CDC}$, has been determined on the basis of (1) a national prevalence study (NIDEP) in a representative sample of 72 hospitals, and (2) an incidence study in which data about the use and duration of insertion of central venous catheters (CVC) and of catheter-associated BSI were collected from 25 ICUs participating in the hospital infection surveillance system (KISS+) and analyzed.

The first study showed primary BSI to be the fourth most frequent nosocomial infection (8.3\% of all nosocomial infections). With an ICU prevalence of $2.1 \%$, primary BSI comprises $12.8 \%$ of all nosocomial infections observed in ICU patients. The second study showed a $60.4 \%$ prevalence of CVC use in German ICUs. An analysis of 55,400 CVC-days in 14,988 ICU patients in the KISS hospitals yielded 2.2 CVC-associated BSIs per 1,000
CVC-days $\left(\mathrm{CI}_{05}, 1.8-2.6\right)$. The rates of CVC-associated BSI on individual hospital wards were very variable and indicate a reduction potential. A reduction in the number of infections of approximately one third would prevent 1,000 to 1,400 deaths due to CVCassociated BSI annually, as well as approximately 40,000 to 60,000 extra days of hospital stay and the associated costs.

FROM: Gastmeier P, Weist $\mathrm{K}$, Ruden H. Catheter-associated primary bloodstream infections: epidemiology and preventive methods. Infection 1999;27(suppl 1):S1-S6. 